\title{
Vagal Maneuvers, a Unique Osteopathic Addition to the ACLS Armament: Review
}

\author{
Richard M. Pescatore II ${ }^{\mathrm{a}}$, Benjamin N.Abo ${ }^{\mathrm{b}}$, Matthew C. Ruppel ${ }^{\mathrm{c}}$, Jessica M.Smolar ${ }^{\mathrm{a}}$, Robert M. Sklar $^{\mathrm{c}}$, Stephen A. \\ Pulley
}

${ }^{a}$ Department of Emergency Medicine, Cooper University Hospital, Camden, NJ, ${ }^{\mathrm{b}}$ Department of Emergency Medicine, Mount Sinai Medical Center, Miami Beach, FL, ${ }^{\mathrm{c} D e p a r t m e n t ~ o f ~ E m e r g e n c y ~ M e d i c i n e, ~ P h i l a d e l p h i a ~ C o l l e g e ~ o f ~ O s t e o p a t h i c ~}$ Medicine, Philadelphia, PA

Address for Correspondence: Richard M. Pescatore II, Email: rmpescatore@gmail.com

\begin{abstract}
In the United States, there are more than half a million people diagnosed with supraventricular tachycardia (SVT). There are approximately 89,000 new presentations of SVT a year, many of them presenting to U.S. emergency centers for initial management of their tachydysrhythmia. The purpose of this article is to describe the wide range of effective techniques for the initial non-pharmacologic management of supraventricular tachycardia, and to discuss their mechanisms of action and potential drawbacks. Additionally, we will introduce a commonly used Osteopathic Manipulative Therapy as a potential firstline treatment option for hemodynamically stable SVT.
\end{abstract}

Key words: Disease Management, Emergencies, Osteopathic Manipulation, Supraventricular Tachycardia

\section{Introduction}

In the United States, there are more than half a million people diagnosed with supraventricular tachycardia (SVT).There are approximately 89,000 new presentations of SVT a year, many of them presenting to U.S. emergency centers for initial management of their tachydysrhythmia [1]. In the emergency setting, treatment of hemodynamically stable patients proceeds along the widely accepted Advanced Cardiovascular Life Support (ACLS) pathway, and can include physical maneuvers, pharmacologic intervention, or electrical cardioversion [2]. Since the introduction of adenosine, a primary medication particularly effective for the treatment of SVT, emergency physicians have tended to neglect physical maneuvers due to assumed time cost and unfamiliarity [2]. Vagal maneuvers, however, represent an effective and safe method for termination of supraventricular tachycardias [3]. Various clinical and laboratory studies have demonstrated vagal maneuvers to activate increased parasympathetic tone, thereby slowing cardiac conduction [4]. The purpose of this article is to describe the wide range of effective techniques for the initial non-pharmacologic management of supraventricular tachycardia, and to discuss their mechanisms of action and potential drawbacks. Additionally, we will introduce a commonly used Osteopathic Manipulative Therapy as a potential first-line

Manuscript received: $12^{\text {th }}$ Apr 2015

Reviewed: $24^{\text {th }}$ Apr 2015

Author Corrected: $4^{\text {th }}$ May 2015

Accepted for Publication: $20^{\text {th }}$ May 2015

International Journal of Medical Research and Review treatment option for hemodynamically stable SVT. The "V-Spread" technique presents a potentially effective and particularly safe initial intervention and could be added to the treatment algorithm for stable, narrow-complex tachydysrhythmias in the emergent setting.

\section{Discussion}

SVT is a general term, and its common use within the ACLS guidelines and introductory cardiology literature often creates confusion for students and practitioners. Dysrhythmias such as sinus tachycardia and atrial fibrillation represent distinct etiologies. Their treatment pathways differ from accepted treatment of regular, narrow-complex tachycardias. We have excluded their discussion from this article. It is important to note that treatment of supraventricular tachycardia, as it is defined within American Heart Association (AHA) recommendations [2], focuses on the management of the most common form of SVT-atrioventricular (AV) nodal reentrant tachycardia (AVNRT).

AVNRT is a consequence of a dual AV nodal physiology created when two competing pathways for electrical conduction arise between the atria and ventricles. Aberrant conduction can cause a re-entrant circuit within the AV node. This can cause patients to present to the emergency department with symptoms that may include palpitations, chest pain, dyspnea, anxiety, light headache, weakness, and diaphoresis [5]. The condition is more Available online at: www.ijmrr.in 436 | $\mathrm{P}$ a g e 


\section{Review Article}

common in women $(75 \%)$ than men. Most patients seek emergency medical care during the fourth or fifth decade of life [6].

After identification of AVNRT, the most recent American Heart Association ACLS guidelines provide for the use of vagal maneuvers in the initial management of a hemodynamically stable patient [2]. Recommended maneuvers include carotid massage and theValsalva maneuver. As up to $27 \%$ of SVT presentations may convert with such simple maneuvers alone, it is nearly certain that use of vagal techniques as primary interventions will remain [7].

\section{Valsalva Maneuver}

The ValsalvaManeuver should be performed with the patient in the supine position [7,8]. The patient is asked to forcibly exhale against a closed mouth or by asking the patient to bear down, both for at least 15 seconds. Ideally, the intrathoracic pressure should be measured, though this is impractical in the emergency setting. Exhalation against a closed glottis causes an increase in intrathoracic pressure that incites a sequence of rapid changes in preload and afterload stress [9]. As preload and venous return fall, stroke volume follows suit via the FrankStarling mechanism. Pressure on the thoracic aorta induces a baroreceptor reflex that transiently slows the heart rate during the maneuver. On release of intrathoracic pressure, sudden increase in diastolic filling and concomitant stroke volume increase induces an arterial pressure overshoot and a relative compensatory bradycardia [10]. The efficacy of the Valsalva Maneuveris variable,with four small studies reporting reversion success rates ranging from 6-54\% [11]. Part of this variability may be patient effort-dependent. One technique to assure, or at least judge the patient's effort, is to place the practitioner's fist into the patient's abdomen and have the patient hold their breath and push their abdominal musculature against the fist. A weak effort can be detected and the patient coached to increase the effort. This method also gives the patient a focus for their effort. Despite a potentially low success rate, the Valsalva Maneuver is safe and takes little time with correct application.

\section{Carotid Massage}

Perhaps the most utilized of vagal maneuvers, carotid massage consists of five seconds of circular massage on the carotid artery at the level of the carotid bulb. Pressure at this location is thought to cause baroreceptor stimulation, which is transmitted via cranial nerve IX, the glossopharyngeal nerve, to the solitary nucleus (NTS) embedded within the medulla oblongata. The NTS in turn modulates autonomic input to the viscera, and causes parasympathetic impulses to be conducted via cranial nerve $X$, the vagus nerve. Vagal innervation of the atrioventricular node is inhibitory, and causes variable rates of obliteration of AVNRT. It has been known since the early part of this century that the autonomic nervous system can profoundly affect AV conduction [12], and it has been demonstrated that the nerves on the left side primarily control AV conduction, whereas those on the right govern SA rate [13]. As such, it is a reasonable practice in efficacy for the emergency physician to direct carotid massage efforts to the patient's left side. Waxmen et al [14] showed a $48.5 \%$ conversion rate of SVT with carotid massage, however additional studies have reported efficacy between $11.8-22 \%$ [7,15].

Significantly, this procedure is not without risk. The most common adverse effect of carotid massage is hypotension [16]. Although the incidence of hypotension is relatively rare $(<1 \%)$, other adverse events associated with carotid massage include ventricular tachycardia [17], hemiplegia [18], coronary artery spasm [19], thromboembolic stroke, prolonged asystole, and ventricular fibrillation [16]. While current ACLS teachings warn students to use caution when performing carotid massage in patients greater than 55 years old, it is clear that the procedure still carries some small risk to a patient already in extremis. The absence of carotid bruits should always be noted and documented.

\section{Facial Immersion}

Facial immersion in ice water represents a less-studied and far less frequently used treatment option for initial management of stable tachydysrhythmias. Also known as the "Diving Reflex," facial immersion induces a profound bradycardia and peripheral vasoconstriction. The reflex is thought to be initiated by stimulation of afferent nerve endings in the mouth and nose which induces sympathetic stimulation of peripheral vessels and a significant simultaneous vagal stimulation to the heart [20]. Previous small investigations have demonstrated that ice water applied to the face of a pediatric patient for five seconds can hold up to a $96 \%$ conversion rate [21]. While the application of ice water is safe and potentially effective, it presents technical challenges to adequately perform. Additionally, more research, particularly in the adult population, is needed.

\section{Ocular Pressure}

The vagal effect of ocular pressure is caused by stimulation of the extraocular muscles. Direct pressure on the globe induces an oculocardiac reflex mediated by the 


\section{Review Article}

vagus nerve via the trigeminal nerve, $\mathrm{CN} \mathrm{V} \mathrm{[22].} \mathrm{While}$ ocular pressure has shown efficacy in mediating vagal tone [23], its use in the management of SVT has waned due to concerns over retinal detachment $[24,25]$. There are anecdotal reports of the usefulness of ocular pressure when other measures have failed [26]. Additional research into the effectiveness and safety profile of ocular pressure for the termination of supraventricular tachydysrhythmias is warranted.

\section{Digital Rectal Massage}

Digital Rectal Massage (DRM) is an efficacious and rapid technique that may be employed in the termination of SVT [27]. The rectum is supplied with parasympathetic nerve fibers from the second, third, and fourth sacral segments [24]. Afferent impulses stimulated via rectal massage are transmitted through the pelvic splanchnic nerves and to secondary afferents en route to the brainstem and thalamus via the sacral segments [28].

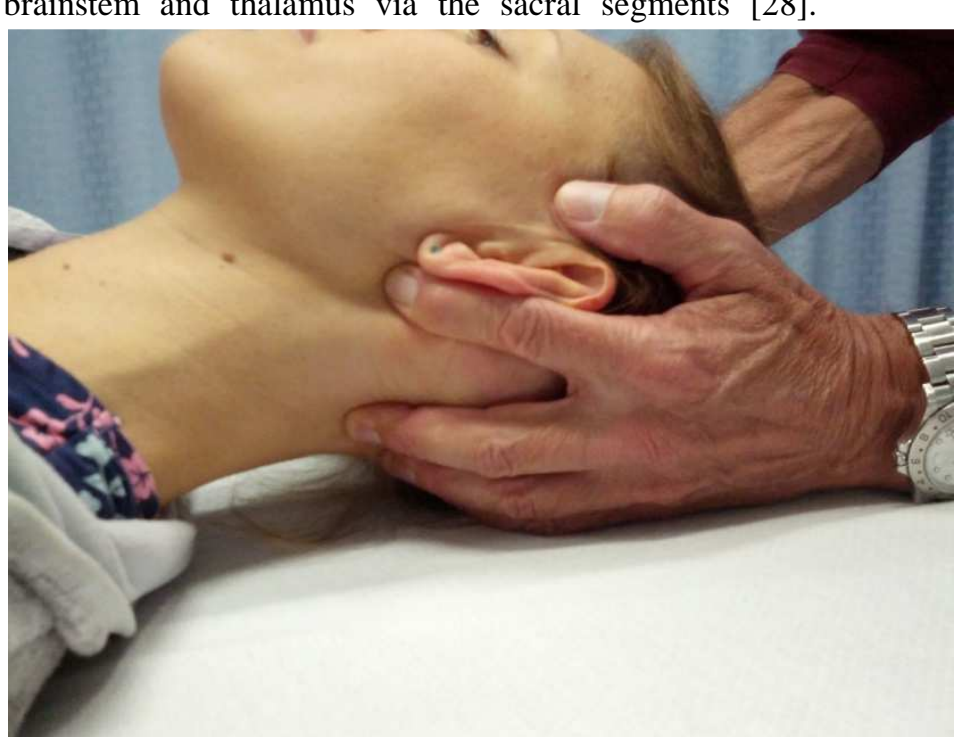

Once the thalamus is signaled, vagal stimulation is accomplished via efferentsignaling through the anterior and medial hypothalamus [29]. DRM may be preferable to other techniques due to its low risk for the complications associated with other vagal maneuvers. Recent publications have suggested the use of digital rectal massage when other vagal maneuvers may be inappropriate or difficult to employ [30].

\section{V-Spread Technique}

The V-Spread Technique represents a long-taught technique in Osteopathic medical schools where a traction force is applied across the diameter of theoccipitomastoid grooves bilaterally in an attempt to relieve myofascial restriction. Release of the occipitomastoid suture induces a direct parasympathetic reflex by the vagus nerve to influence the cardiac rate [31].

Figure 1 : V-Spread Technique applied to the occipitomastoid suture of a healthy volunteer nurse.
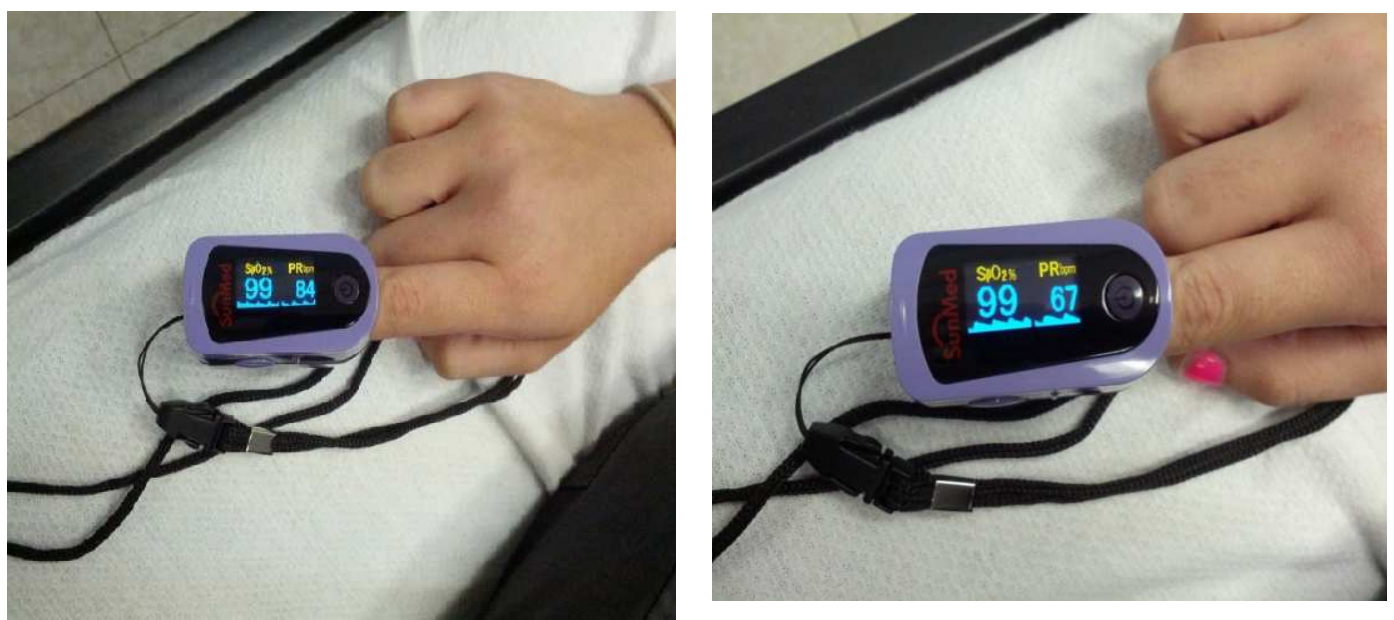

Figure 2: Before-and-after pulse oximetry device readings after five seconds of V-Spread Technique application in a healthy volunteer nurse. 
In contrast to carotid massage, the $\mathrm{V}$-Spread Technique directly impacts the vagus nerve at its eruption from the jugular foramen, enabling the practitioner to address the parasympathetic alignment of AVNRT. No studies yet exist quantifying the effectiveness of the V-Spread technique in the emergent management of ANVRT, however the anatomic and physiologic basis for its implementation is sound, and the procedure is welltolerated by patients with little of the risk encountered with the use of carotid massage

At the time of publication, no strong studies exist that quantify the effectiveness of the V-Spread Technique for treatment of stable narrow complex tachycardias, and evidence of the procedure's efficacy remains hypothetical and anecdotal. V-Spread and occipitomastoid suture manipulation represent a safe and potentially effective initial intervention in cardiovascular life support and further investigations are warranted regarding its use in the emergency setting.

\section{Conclusion}

The prevalence of supraventricular tachycardias and the incidence of their presentation to emergency centers across the United States pose an opportunity for nonpharmacologic healing and demands familiarity with those techniques. Understanding the anatomy and pathophysiology of SVTs, particularly AVNRT, allows the emergency practitioner to intervene quickly and safely with the most basic of tools. Carotid massage, Valsalva maneuver, facial immersion in ice water, ocular pressure and digital rectal massage are excellent and accepted techniques for initial intervention. V-Spread Technique represents apotential additional primary treatment of stable supraventricular tachycardia.

Funding: Nil, Conflict of interest: None initiated. Permission from IRB: Yes

\section{References}

1. Orejarena LA, Vidaillet H Jr, DeStefano F, Nordstrom DL, Vierkant RA, Smith PN, Hayes JJ.Paroxysmal supraventricular tachycardia in the general population.J Am Coll Cardiol. 1998 Jan;31(1):150-7.

2. Neumar RW, Otto CW, Link M, et al. Adult Advanced Cardiovascular Life Support: 2010 American Heart Association Guidelines for Cardiopulmonary Resuscitation and Emergency Cardiovascular Care. Circulation. 2010 Nov;122:S729-67.

3. Muller G, Deal B, Benson DW. "Vagal Maneuvers" and adenosine for termination of atrioventricular reentrant tachycardia. Am J Cardiol. 1994 Sept;1(74):500-3.
4.. Smith GD, Fry MM, Taylor D, MorgansA, Cantwell $K$. Effectiveness of the valsalva maneuver for reversion of supraventricular tachycardia. Cochrane Database of Systematic Reviews. 2015 Feb;18(2).

6. Ganz LI, Friedman PL. Supraventricular tachycardia. N Engl J Med. 1995;(332):162-73.

7. Akhtar M, Jazayeri MR, Sra J, Blanck Z, Deshpande S, Dhala A. Atrioventricular nodal reentry: clinical, electrophysiological, and therapeutic considerations. Circulation. 1993; (88):282-95.

8. Lim S, Anantharaman V, Teo W, Goh P, Tan A. Comparison of treatment of supraventricular tachycardia by Valsalva maneuver and carotid sinus massage.Annals of Emergency Medicine. January 1998; 31(1):30-35.

9. Taylor DM, Wong LF. Incorrect instruction in the use of the Valsalva maneuver for paroxysmal supraventricular tachycardia is common. Emerg Med Australas. 2004 Aug;16(4):284-7.

10. Porth CJ, Bamrah VS, Tristani FE, Smith JJ. The Valsalva maneuver: mechanisms and clinical implications. Heart Lung. 1984 Sep;13(5):507-18.

11. Junqueira, LF. Teaching cardiac autonomic function dynamics employing the Valsalva (Valsalva-Weber) maneuver. Adv Physiol Educ. 2008 Mar; 32(1):100-6.

12. Smith G. Management of supraventricular tachycardia using the Valsalva maneuver: a historical review and summary of published evidence. Euro J Emerg Med. 2012 Dec;19(6):346-52.

13. Rothberger CJ, Winterberg H. UberdieBeziehungen der Herznervenzuratrioventrikularenautomatie (nodal rhythm). Arch Ges Physiol. 1910;(135) 559-604.

14. Martin, P. The Influence of the Parasympathetic Nervous System on Atrioventricular Conduction. Circulation Research. 1988;(41):593-9.

15. Waxman MB, Wald RB, Sharma AD, et al: Vagal techniques for termination of paroxysmal supraventricular tachycardia. Am J Cardiol. 1980;(46):655-64.

16. Ornato JP, Hallagan LF, Reese WA, et al. Treatment of paroxysmal supraventricular tachycardia in the emergency department by clinical decision analysis. Am J Emerg Med. 1988;(6):555-60. 


\section{Review Article}

17. Richardson DA, Bexton R, Shaw FE, Sten N, Bond J, Kenny RA. Complications of carotid sinus massage-a prospective study of older patients. Age and Ageing.2000;(29):413-7.

18. Matthews OA. Ventricular tachycardia induced by carotid sinus stimulation. J Maine Med Assoc. 1969;(60):135-6.

19. Askey JM. Monoplegia following carotid sinus massage. J Intern Med. 1994;(235):379-81.

20. Nishizaki M, Yamawake N, Arita M. Coronary artery spasm induced by carotid massage. Heart. 2000;(84): E2.

21. Finley JP, Bonet JF, Waxman MB. Autonomic pathways responsible for bradycardia on facial immersion. Journal of Applied Physiology.1979;(47):1218-22.

22. Aydin M, Baysal K, Kucukoduk S, Cetinkaya F, Yaman S. Application of ice water to the face in initial treatment of supraventricular tachycardia. Turk J Pediatr. 1995 Jan-Mar;37(1):15-7.

23. Arnold RW. The human heart rate response profiles to five vagal maneuvers. Yale Journal of Biology and Medicine. 1999;(72): 237-44.

24. Yamashita M. Oculocardiac reflex and the anesthesiologist. Mideast J. Anesthesiology, 1986;(8):399-415.
25. Bolton EC. Dysrhythmias. Emergency Medicine: Concepts and Clinical Practice. St Louis, MO: CV Mosby CO, 1983. 887-916.

26. Silverman ME. Recognition and treatment of arrhythmias. Principles and Practice of Emergency Medicine. Philadelphia, PA: WB Saunders CO, 1978. 891-921.

27. Schwam E. The Eyes Have It. AcadEmerg Med. 2004 Aug 8;(11):842-3.

28. Roberge R, Anderson E, MacMath T, Rudoff J, Luten R. Termination of Paroxysmal Supraventricular Tachycardia by Digital Rectal Massage. Annals of Emergency Medicine. 1987;(16):139-41.

29. Adams RD, Victor M. Principles of Neurology, ed 2. New York, NY: McGraw-Hill, 1981. 363-83.

30. Dejong RN. The Neurologic Examination, ed 4. Philadelphia, PA: Harper and Row, 1979. 507.

31. Bosker G. The Emergency Medicine Reports textbook of adult and pediatric emergency medicine: principles, protocols, pathways. Atlanta, GA: American Health Consultants, 2002. 936.

32. Nicholas A, Nicholas E. Occipitomastoid Suture Pressure. Atlas of Osteopathic Techniques. 2008;(1):398.

\section{How to cite this article?}

Richard M. Pescatore II, Benjamin N Abo, Matthew C. Ruppel, Jessica M Smolar, Robert M Sklar, Stephen A. Pulley. Vagal Maneuvers, a Unique Osteopathic Addition to the ACLS Armament: Review. Int J Med Res Rev 2015;3(4):436-440. doi: 10.17511/ijmrr.2015.i4.076. 